\title{
Libidinosa amor. Sobre algunes fonts llatines en Lo somni
}

\author{
Libidinosa amor. On some Latin sources in Lo somni
}

\author{
Sònia Gros Lladós \\ sgroslla@gmail.com \\ UNED (Girona)
}

Resum: En aquest treball s'exploren algunes referències dels llibres III i IV de Lo somni al voltant de «l'amor de fembres» $\mathrm{i}$ els efectes perniciosos de la luxúria immoderada, des de la perspectiva de les fonts llatines emprades en el text català. L'anàlisi de la reutilització metgiana d'algunes fonts permet examinar els recursos formals de la seva escriptura, així com aprofundir en les relacions de Metge amb els textos clàssics $i$ italians. Lo somni evidencia una nova perspectiva literària $i$ una clara actitud filògina en l'estela de les relectures que els grans mestres del Trecento, Petrarca i Boccaccio, havien realitzat de clàssics llatins com Valeri Màxim.

Paraules clau: Bernat Metge, Lo somni, Petrarca, Boccaccio, Valeri Màxim.

\begin{abstract}
This paper explores some references in books III and IV of Lo somni on the question about «l'amor de fembres» and the pernicious effects of immoderated lust, from the perspective of the Latin sources used in the Catalan text. The analysis of Metge's reuse of some sources allows to examine the formal resources of his writing, as well as to delve into the connections of Bernat Metge with classical and Italian texts. Lo somni shows a new literary perspective and a clear philogynist attitude imitating the re-readings that the great masters of Trecento, Petrarch and Boccaccio, had made of Latin classics such as Valerius Maximus.
\end{abstract}

Keywords: Bernat Metge, Lo somni, Petrarch, Boccaccio, Valerius Maximus. 


\section{Introducció}

La qualitat literària de Lo somni és unànimement reconeguda, més enllà de la controvèrsia sobre el caràcter humanístic o la finalitat específica de l'obra (Cingolani 1999, 2006; Badia 1999; Butinyà 2007, 2011). En opinió de Ruiz Simon (2002), el text de Bernat Metge abraça la totalitat de la filosofia, a partir del model del Somnium Scipionis. Metge dedica la primera part de l'obra a la filosofia racional, amb la qüestió de la immortalitat de l'ànima, mentre que els dos darrers llibres del diàleg estan centrats en la filosofia moral, amb la discussió sobre l'amor humà, seguint l'estela d'un conjunt variat d'autors cristians, clàssics i italians (Butinyà 1994), entre els quals sobresurten Ciceró i Petrarca -en particular, el Secretum (Fenzi 2012). La presència del diàleg petrarquesc va ser suggerida per Martí de Riquer en els seus primers treballs sobre Lo somni i hi van aprofundir en els anys 90 del segle passat estudiosos com Júlia Butinyà (1994). Actualment hi ha un consens entre els especialistes sobre la rellevància del Secretum en l'obra de Metge, el qual s'ha arribat a valorar com «la clau de les darreres lectures del clàssic català» (Badia \& Gómez 2015-16: 26, n. 5).

En aquest treball ens proposem d'explorar algunes de les referències que Metge posa en boca de diferents personatges al voltant de «l'amor de fembres», relacionades amb la luxúria immoderada i els seus efectes perniciosos. L'anàlisi de la reutilització metgiana de les fonts del text ens permetrà, d'una banda, examinar els recursos formals emprats conscientment en la seva escriptura, així com aprofundir en les relacions del barceloní amb els textos clàssics $i$ italians, clau de volta per a una comprensió més afinada del sentit de l'obra.

La llarga conversa sobre l'amor humà que ocupa gran part del tercer i últim llibre del Secretum és la referència que emmarca aquesta secció del diàleg metgià (Butinyá 1994, Gros 2013). L'apel lació dogmàtica a la veritat de l'Agustí de Petrarca -In rebus contrariïs opinio diversa; veritas autem una atque eadem semper est (I, 6)- ressona inequívocament en la resposta a Bernat de part de Tirèsies: «La veritat, però, no has mudada; car una matexa és» (2007: 278) (Gros 2013: 75-76). Així com la breu rèplica de Bernat: «ab aquesta opinió vull morir» (2007: 278). ${ }^{1}$ Caldrà interpretar, doncs, les referències puntuals d'autors diversos que anirem assenyalant dins el marc que proporciona el sentit global del text. Segueix Metge, d'aquesta manera, la lliçó del mestre Petrarca, com subratlla Fenzi: «Bernat segue Petrarca non solo quando lo cita e ne riprende parole e schemi, ma anche quando si volge agli autori ai quali proprio Petrarca lo rimandava» (2012: 87). El reaprofitament de les lectures dels clàssics per part de Metge està sotmès, a la manera petrarquesca, a la intencionalitat pròpia de la seva escriptura, en un tret extremadament revelador d'una actitud no reverencial, que va més enllà del subjectivisme manifestat per l'aretí en el Secretum.

1 En aquest passatge, com recorda Butinyà (2007: 279), Metge està seguint de ben a prop el llibre III del Secretum, allà on Agustí s'indigna perquè Francesco utilitzava els mateixos mots del De senectute (XXIII, 85), apropiats a la divinitat, aplicats a les dones. Citem els textos de Lo somni a partir de l'edició de Júlia Butinyà (2007). 
El material mític que Metge incorpora en el text de Lo somni rep un tractament que es distancia visiblement de la tradició medieval. Per a Friedlein, Metge presenta una nova utilització, ben conscient, del mite com a saber poètic, per oposició al saber dogmàtic i filosòfic i al de l'experiència d'altres personatges de l'obra (2004: 83). No observem, en efecte, traces d'una intenció moralitzant ni d'una cristianització del mite clàssic en el relat nu, que Orfeu fa de la seva història. Pel que fa al Tirèsies metgià, personatge del qual quedava pendent un estudi en profunditat, així com la relació amb les fonts emprades -com va assenyalar Júlia Butinyà (2007)-, ha estat explorat recentment (Badia \& Gómez 2015-16). Aquests estudiosos conclouen que el relat ha estat bastit no sobre el model ovidià, sinó sobre el canemàs del que anomenen «tradició mitogràfica» (2015-16: 34). Tirèsies esdevé, al seu parer, una creació innovadora de Metge, que configura un personatge ambigu i aliè a la cortesia, amb una desmesura i un comportament que «conviden a la dissensió i fan retòricament viable la segona part del llibre III de Lo somni i tot el IV» (2015-16: 35).

\section{Libidinosa amor}

El llibre III de Lo somni s'inicia amb la intervenció d'Orfeu, ${ }^{2}$ un dels interlocutors de Bernat, que ofereix a tall de presentació la narració de la seva dissortada història. El poeta traci indica breument la filiació i la seva activitat professional, i passa tot seguit a narrar la pèrdua d'Eurídice:

\footnotetext{
Muller haguí fort bella, apel lada Eurídices, la qual era a mi pus cara que la vida. Per sa desaventura, anant-se deportar prop la riba de un riu, fou de libidinosa amor requesta per Aristeu, pastor; e com ella, fugint a aquell per un prat, fos morduda e verinada en lo taló per una serp aquí amagada, encontinent morí e devallà en infern (2007: III, 162).
}

Com s'ha posat en relleu (Butinyà 2007: 163), les fonts emprades per Metge per a aquest passatge són les Metamorfosis d'Ovidi (X i XI), completades amb detalls del llibre IV de les Geòrgiques de Virgili i alguns autors medievals com Boeci. La Genealogia (V, 12) i Il Commento han estat també suggerides com a inspiració d'aquest breu relat, que subratlla el desig incontrolable d'Aristeu, el rebuig ferm de la nimfa i la consegüent fugida i mort accidental d'Eurídice. La narració de l'Orfeu de Metge eludeix, com fa notar Butinyà, la interpretació moralitzant present en algunes versions com la de la Genealogia i, ben al contrari, anticipa la defensa de la dona que desenvoluparà àmpliament en el llibre IV.

El mite d'Orfeu havia estat extraordinàriament difós en el període medieval mitjançant tant les fonts clàssiques (Virgili, Ovidi, Sèneca), com les versions posteriors de Fulgenci i Boeci, i els nombrosos comentaris al llarg de tota l'edat mitjana, que aviat deriven cap a una cristianització del mite. Les primeres versions vernacles apareixen al segle XIV amb l'anònim Sir Orfeo anglès, anterior al 1330, però el triomf de l'humanisme propiciarà el retorn a recreacions d'inspiració clàssica com La festa di

2 Sobre el significat i la interpretació de les figures mitològiques d’Orfeu i Tirèsies, vegeu Butinyà (2006: 30-31).

SCRIPTA, Revista internacional de literatura i cultura medieval i moderna, núm. 18 / desembre 2021 / pp. 1-14 ISSN: 2340-4841 $\cdot$ doi:10.7203/SCRIPTA.18.22350 
Orfeo de Poliziano (1471). Entre aquestes primeres versions vernacles comptem amb la de Lo somni, una extraordinària primícia quant al tractament rigorós del material mític segons els testimonis canònics de Virgili i Ovidi, i quant als plantejaments ideològics de l'autor.

Com observem, en el relat anterior de Lo somni Metge responsabilitza únicament Aristeu d'una passió perniciosa, causa, a més, de la desgràcia del personatge femení. El mot originari en llatí, libidinosus, presenta en els autors clàssics un matís clarament pejoratiu i implica un desig o plaer, en particular sensual o eròtic, desordenat, excessiu, capriciós o arbitrari. ${ }^{3}$ En llatí s'utilitzen habitualment dos mots per designar el desig sexual, cupido i libido. El segon amb un significat més pròxim a 'luxúria'. En els autors llatins libido, i els seus derivats com libidinosus, presenten diferents valors, entre els quals dominen les connotacions morals negatives, com succeeix en el cas del verb libidinari (Moreno 2011: 144). ${ }^{4}$ En català, es tracta d'una de les primeres ocurrències del cultisme libidinós, segons atesten el DCVB i el CiCA. ${ }^{5}$ Segons els autors clàssics, el desig irrefrenable d'allò que és impossible o prohibit és causa d'actes terribles, com l'incest, la traïció, l'adulteri o la violació, en el cas d'Aristeu. El desig immoderat es relaciona amb tota mena d'excessos i en autors que defensen la moral tradicional romana, com ara Sèneca, s'estableix una relació inequívoca amb la riquesa i el llibertinatge. Els poetes amatoris propugnen que el desig sexual no és exclusiu dels homes, sinó que ben al contrari afecta també les dones. En l'Ars, Ovidi arriba a explicar que la pulsió sexual és més forta en les dones (Ars I, 276-282), les quals són capaces d'ocultar-la millor, que en els homes, en els quals troba un fre (Ars I, 281-282). Tanmateix, malgrat aquestes consideracions, conservem una munió de testimonis, molts d'ells ovidians, d'exemples en què els barons, arrossegats per un desig excessiu i incontrolat, exerceixen la violència sobre una dona. Sovint la violació, o intent de violació com el d'Aristeu, es produeix aprofitant l'aillament i indefensió de la víctima en un entorn idíl lic, on no és estrany trobar-hi un estany, un riu o una font. És el cas de Dafne, d’Hermafrodit, d'Aretusa o de Cal listo, i d'Eurídice.

No pren Metge directament l'anècdota de la mort d'Eurídice de la brevíssima referència d'Ovidi - nam nupta per herbas / dum nova naiadum turba comitata vagatur, / occidit in talum serpentis dente recepto (Met. X, 8-10)-, de la qual tan sols conserva amb fidelitat el lloc de l'escena (per herbas) i el detall de la mossegada de la serp al taló. Més allunyada encara de la narració metgiana es troba la versió de les Geòrgiques, en què, per boca de Cirene, la mare del pastor Aristeu, es relata la fi desventurada d'Eurídice: Illa quidem, dum te fugeret per flumina praeceps, / immanem ante pedes bydrum moritura puella / servantem ripas alta non vidit in herba (IV, 457-459). Tanmateix, convé tenir present que en les Geòrgiques aquest episodi es relata a manera d'explicació de l'epidèmia que pateixen les abelles d'Aristeu, càstig

3 Així ho recullen els diccionaris: Lewis and Short (http://www.perseus.tufts.edu/hopper/ text?doc=Perseus\%3Atext\%3A1999.04.0059\%3Aentry\%3Dlibido); Gaffiot (1934: 907); Ernout \& Meillet (2001: 367).

4 Així, en el cas d'Horaci: libidinosus immolabitur caper / et agna Tempestatibus (Ep. 10, 23-24). En aquest cas, el terme apareix referit a un animal símbol de la luxúria, com és el boc.

5 Corominas dona per a la primera aparició en castellà la data de 1444, més tardana que la de Lo somni (1987: 359).

SCRIPTA, Revista internacional de literatura i cultura medieval i moderna, núm. 18 / desembre 2021 / pp. 1-14 ISSN: 2340-4841 $\cdot$ doi:10.7203/SCRIPTA.18.22350 
dels déus per haver provocat la mort de la nimfa. En aquesta darrera versió de Virgili, el pastor és descarregat de qualsevol responsabilitat per la seva mare: l'herba és alta, la serp enorme, la noia està destinada a morir; fins i tot es percep una velada acusació de culpa envers la impetuositat o precipitació de la nimfa, causant de la seva dissortada fi, en no haver vist el perill ante pedes.

La de Virgili és la versió a què remet explícitament Boccaccio en la Genealogia, tot i que omet la citació literal de l'autor llatí, com sí fa en altres moments en què relata successos relacionats amb Aristeu. És més, Boccaccio matisa significativament el relat, diluint la responsabilitat de la nimfa en el desenllaç: Hanc [Euridicem] cepit amare Aristeus pastor, et die quadam, dum secus ripas Hebri cum Dryadibus spatiaretur, eam capere voluit, que fugiens pede serpentem inter herbas latitantem pressit, qui revolutus in eam venenato morsu interemit $(G e n . \mathrm{V}, 12)$. Tanmateix, Boccaccio tot seguit subministra una interpretació moralitzant de la història, seguint -segons declara- Fulgenci, en la qual Eurídice és identificada amb l'apetit sensual i Aristeu amb la virtut:

\begin{abstract}
Hic insuper Euridicem habet in coningem, id est naturalem concupiscientiam, qua nemo mortalium caret; hanc per prata vagantem, id est per temporalia desideria, amat Aristeus, id est virtus, que eam in laudabilia desideria trahere cupit; verum ips a fugit, quia naturalis concupiscientia virtuti contradicit, et dum fugit virtutem a serpente occiditur, id est a fraude inter temporalia latente. (Gen. V, 12)
\end{abstract}

Quant a Fulgenci, un dels mitògrafs més influents en el període medieval, la seva versió oferia una interpretació al legòrica del mite d'Orfeu des d'una perspectiva musical i literària, mancada d'elements religiosos (Mit. III, 10). Seran els comentaristes posteriors, com Isidor de Sevilla o Rabanus Maurus, els que adaptaran la interpretació de Fulgenci als seus interessos particulars (González 2003: 12). La versió de Boeci (De cons.Phil. III, m. XII, 1-58), la primera que subministra una interpretació al legòrica de tipus eticofilosòfica, en canvi, omet la persecució d'Aristeu i la causa de la mort d'Eurídice.

Aquestes relectures del mite clàssic se'ns mostren ben diferents a la que llegim en Metge, com ja van assenyalar Martí de Riquer i Júlia Butinyà. La identificació del desig luxuriós desordenat amb un comportament exclusivament masculí, com en l'episodi d'Aristeu i Eurídice, no és un fet aillat en Lo somni. Quan Bernat respon a la diatriba de Tirèsies contra les dones, manifesta una actitud similar. Per a Tirèsies, que s'atribueix l'autoritat de parlar com a dona remetent explícitament al seu passat, «Fembra és animal inperfet, de passions diverses desplasents e abhominable passionat, no amant altra cosa sinó son propri cors e delits» (2007: 192). Aquesta representació metgiana de Tirèsies, manllevada directament del Corbaccio, és certament molt diferent a la que apareix en les Metamorfosis ovidianes (III, 316-388), en què el savi endeví tan sols certifica l'opinió de Júpiter que les dones experimenten major plaer que els homes en l'acte sexual. La versió d'Ovidi manca de matisos còmics, més enllà del propi tema de discussió, i ofereix una imatge digna del sacerdot.

El discurs misogin de l'endeví grec de Lo somni, construit sobre el Corbaccio, recull tots els tòpics 
sobre els vicis femenins, completats en ocasions amb el recurs a la font llatina original, Juvenal. La luxúria n'és un d'especial rellevància: «L'ardor de luxúria que elles han no la’t vull dir a present, car massa $\mathrm{m}$ costa, segons que damunt has oÿt [...] No és cosa que elles no assagen per poder satisfer a lur apetit» (2007: 202). Com s'ha fet notar (Bastardas 1993: 12), Tirèsies mostra una clara preferència pel terme fembra respecte a dona (22/5), per designar una 'persona de sexe femení', justament al contrari del que succeeix amb el personatge de Bernat (5/46), mentre Orfeu utilitza sempre el terme dona. L'explicació d'aquesta distribució sembla relacionada amb la font utilitzada, com ara en la intervenció de Tirèsies, bastida literalment, com documenta Bastardas, sobre el Corbaccio: la femmina e animale imperfetto, passionato da mille passioni spiacevoli e abominevoli $(71,200)$.

La crítica del desig sexual irrefrenable de la dona tenia els seus orígens en els textos grecs i travessa tota la literatura llatina (PROP. III, 9; PETR.). N'és una mostra notòria i molt influent la sàtira VI de Juvenal contra els excessos de les matrones romanes, que Metge rescata literalment en alguns moments del discurs de Tirèsies (Butinyà 2007). La condemna del desig sexual immoderat en les dones va gaudir d'un considerable conreu literari entre alguns autors clàssics que detectem entre les fonts ben conegudes de Lo somni. Els atacs de Ciceró a Clòdia (Cael. XX 47-50), les queixes d'Horaci contra la decadència dels costums (Carm. III 24, 17-30), la crítica del llibertinatge de Sèneca (Phaedr. 204-215) o l'exemple paradigmàtic de lascívia, Messalina (IVV. VI, 50-135; 301-341), que Tirèsies recorda en la seva diatriba misògina.

\section{Multa de laudibus feminarum}

Bernat respon als atacs de Tirèsies contra les dones, i contra la seva amant en particular, en el llibre IV, amb una encesa defensa dels «actes virtuosos e de gran valor, saber e enginy» (2007: 234) femenins, que contraposarà al «mal que comunament és en los hòmens» (2007: 232). L'apologia del comportament de la dona inclou tot un catàleg d'exemples, bastit gairebé de manera literal sobre el model d'una de les Familiares (XXI, 8) de Petrarca. A la font principal, cal afegir, a més, detalls procedents dels Factorum et dictorum memorabilia de Valeri Màxim i de De claris mulieribus de Giovanni Boccaccio (Vilanova 1957: 150-151).

En la vuitena carta del llibre XXI de les Familiares, redactada cap al 1358 i adreçada a l'emperadriu Anna, Petrarca havia evocat un catàleg de dones excelses de l'Antiguitat, com a resposta a una epístola anterior en què la dama l'informava del naixement d'una filla. Entre els exemples que Petrarca subministra, sobresurten les dones il lustres de l'Antiguitat clàssica, grega i romana, però l'escriptor inclou, a més, exemples d'altres pobles antics cèlebres pels seus actes, com Semíramis, Thamiris, Cleòpatra o Zenòbia; fins i tot dones cristianes o figures en les quals convergeixen ambdues tradicions, com les Sibil les o Proba. En la seva epístola, Petrarca subratlla l'excel lència en àmbits diversos, des del saber al valor en la batalla, la pietat o l'amor conjugal. La versió metgiana manté la referència a la majoria de les dones que cita Petrarca, malgrat que n'altera de vegades l'ordre. 
Prescindeix de les mencions de Cleòpatra, la comtessa Matilde o Lívia i hi insereix l'exemplum de Griselda -amb l'esment de la seva traducció al català-, el de les dones d'Israel o el d'Hipo. Substitueix els noms femenins de ciutats gregues i romanes pel de «Barchinona» i tanca el conjunt exemplar de dones excelses amb una menció contemporània com Petrarca, que s'adreçava a l'emperadriu Anna, amb una original variatio del barceloní: la galeria de reines catalanes.

Cap al 1361 Boccaccio inicia la composició del De claris mulieribus, un tractat en llatí, dedicat a Andrea Acciaiuoli, en què presenta un ampli catàleg de dones, majorment paganes, cèlebres per la rellevància dels seus actes. L'obra manifesta una de les preocupacions característiques de l'autor -l'interès per la dona- $i$ es proposa un ensenyament moral per a les receptores del text, com declara explícitament en el Proemi. En aquesta obra Boccaccio es mostra ja allunyat de la tradició medieval dels relats religiosos de dones virtuoses i s'apropa, al contrari, a la línia de vides il lustres de dones de l’Antiguitat clàssica, seguint el model de Valeri Màxim i Livi.

De les accions femenines cèlebres dignes de recordar, algunes tenen relació amb models de castedat femenina, violentada per la luxúria masculina. El terme libidinosus apareix en diverses ocasions en el tractat de Boccaccio, generalment aplicat a personatges masculins: a libidinoso preside; libidinosi Appii, fracta libidinosa spe (LVIII Virgínia); libidinosum principem (LXXXVIII Cleòpatra); libidinosam pruriginem reticentes suam (XCIV Pompeia Paulina) és l'únic exemple en què està referit a la luxúria femenina. El terme libido és molt més freqüent. El mateix succeeix en la font dels Dictorum de Valeri Màxim. De les sis ocurrències que hem detectat, la major part es relaciona amb la lascívia masculina: libidinosi centurionis (6.1.11); libidinoso aspectu (4.3.ext.1); a libidinoso complexu (8.2.2); libidinosus (9.2.ext.3). Això no obstant, el catàleg de Boccaccio inclou dones famoses de virtut moral poc exemplar: Cleòpatra, Popea o Agripina en la història romana; Helena, Clitemnestra o Medea en la mitologia grega. Sobre aquest ampli repertori, Metge opera una selecció d'acord amb les seves preferències estètiques i ideològiques.

Entre els actes virtuosos que Metge presenta, destaquen dos relacionats amb els desitjos eròtics incontrolats masculins. Són els de Lucrècia i Hipo. Si la violació d’un personatge femení és un motiu molt freqüent en els episodis mitològics, i en particular en les Metamorfosis ovidianes, tampoc ens manquen testimonis en l'àmbit de la història romana. De Rea Sílvia a les Sabines, en els orígens de Roma retrobem contínuament relats d'esdeveniments marcats per violacions o agressions sexuals contra les dones. El cas paradigmàtic és el de Lucrècia (LIV. I, 57-58; OV. Fast. II, 795-810), atacada per Tarquini, que l'amenaça amb la mort i la deshonra. L'acció heroica de la matrona, la qual, malgrat que es proclama innocent i obté el reconeixement i comprensió del pare i de l'espòs, se suïcida amb determinació exigint el càstig implacable de l'agressor, constitueix l'acte fundacional de la república. En la concepció tradicional romana, la violació marcava la dona amb un estigma d'infàmia i deshonor, tot i que la víctima fos innocent, i en aquest mateix sentit cal interpretar les queixes de Filomela a les Metamorfosis (Curran 1978: 223-224). Un altre exemple històric -recollit també en el De claris mulieribus (LVIII)- d'intent de violència sexual contra la dona és el de Virgínia, 
de la qual havia intentat apoderar-se el decemvir Api mitjançant argúcies legals. El pare va preferir assassinar-la abans que permetre la violació de la jove (LIV. III, 44, 1-48). Les dones que eviten la violació amb el suïcidi mereixen igualment l’elogi de Valeri Màxim (VI 1, 1-3 ext.).

\section{Els exempla de Lucrècia i Hipo}

D'aquests exemples de castedat femenina (pudicitia) enfront del desig lasciu masculí en l'antiga Roma, Metge tria el de Lucrècia, ben conegut i àmpliament difós, i el d'Hipo, ben al contrari força desconegut $\mathrm{i}$ absent en el model petrarquesc. Coneixem la història de la donzella grega Hipo pel testimoni de Valeri Màxim, el qual segueix fidelment el barceloní, com es pot comprovar amb l'acarament d'ambdós textos:

\begin{abstract}
Graeca femina nomine Hippo, cum hostium classe esset excepta, in mare se, ut morte pudicitiam tueretur, abiecit. Cuius corpus Erythraeo litori adpulsum proxima undis humus sepulturae mandatum ad hoc tempus tumulo contegit: sanctitatis uero gloriam aeternae traditam memoriae Graecia laudibus $s u<m><m>$ is celebrando cotidie florentiorem efficit (VAL. MAX. 6.ext.1).
\end{abstract}

\begin{abstract}
No fou menor ni menys cautelosa guardiana de la sua castedat Hipo, fembra grega fort bella, la qual, com fos presa per enemics en una nau, e veés que la sua castedat no podia conservar sinó per mort, se gità en la mar, e morí. (LS, IV, 244)
\end{abstract}

Valeri Màxim (ca. $15 \mathrm{aC}$ - ca. $35 \mathrm{dC}$ ) dedica uns breus passatges a Lucrècia i Hipo com exemples distingits de pudicitia en els Dictorum et factorum memorabilium, obra redactada cap al $31 \mathrm{dC}$. L'obra de Valeri Màxim va ser àmpliament difosa per tot Europa en el període medieval mitjançant abundants manuscrits llatins, comentaris, traduccions i compilacions, fins al punt d'haver estat qualificada com «il primo arsenale della esemplarità medievale» (Battaglia 1965: 462). Les primeres versions vernacles, que sovint incorporen glosses i comentaris, apareixen a Itàlia des de la primera meitat del segle XIV, una d'elles atribuïda a Boccaccio, bon coneixedor del text llatí. Més tard es donen a conèixer traduccions a l'alemany (1369) i al francès (1375). En conservem una versió al català de Fra Antoni Canals ca. 1395, a partir de la qual es realitzà, cap al 1418-19, la versió al castellà d'Alfonso de Zamora. Com subratlla Helena Rovira,

\footnotetext{
Qualsevol lector dels s. XIV-XV que conegués el català podia llegir en aquesta llengua episodis provinents dels Dicta de Valeri Màxim, algunes vegades amb un reconeixement explícit de la font i altres vegades com a anècdota al ludida per l'autor sense identificar-ne l'origen. De fet, el punt de partida no sempre era el text llatí de Valeri Màxim o la traducció d'Antoni Canals enllestida el 1395 o poc abans, sinó que podien ser altres obres en llatí o en alguna llengua vulgar, sobretot l'italià. (2015: 31)
}

L'exemplaritat i l'encaix amb la mentalitat cristiana n'expliquen la freqüent reutilització en obres escrites i en l'oratòria pública, política i religiosa, en tot l'àmbit europeu. L'admiració pels Dictorum 
continuà entre els autors del primer humanisme. La petjada de Valeri Màxim, l'obra del qual va conèixer a Nàpols a través de Dionigi da Borgo San Sepolcro, en la prosa i el món narratiu de Boccaccio és cabdal. El monjo agustí li proporcionà el seu comentari dels Dictorum perquè el traduís. A Boccaccio se li atribueixen diverses versions vulgars del text de Valeri Màxim, que podrien haver estat realitzades a partir d'un treball de Petrarca de 1326 (Hernández 1997: 76-77). En el cas de Lo somni l'ús d'exempla provinents de l'obra de Valeri Màxim és esporàdic i ben integrat en el conjunt del text metgià. Particularment, en el catàleg de dones il lustres, en què se citen models de dones virtuoses presents igualment en Petrarca i Boccaccio, per bé que l'ordre en què apareixen palesa la presència dels Dictorum (Rovira 2014: 63-65). Els estudiosos subratllen el coneixement directe de Metge de l'obra de Valeri Màxim, ${ }^{6}$ per bé que de vegades hibrida els referents llatins amb altres fonts intermèdies com els trescentistes italians (Butinyà 2007; Rovira 2014).

El lloc que ocupa Lucrècia en els Dictorum, el primer dels exempla de castedat femenina que invoca Valeri Màxim, és coherent amb la primacia que li atorga com a dux Romanae pudicitiae. Tot seguit, l'escriptor presenta un seguit d'exemples de barons romans que castiguen de manera implacable actes d'estupre comesos contra dones de les seves famílies, sovint amb la mort de les víctimes, i incorpora entre els darrers exempla el cas de la jove donzella grega Hipo. El cas de la donzella Hipo és un episodi poc habitual en els textos que reprenen els exempla de Valeri Màxim -entre els textos catalans apareix únicament en Lo somni, en la traducció de Canals i en la Summa de Col Vacions (Rovira 2015: 40)- i es documenta en el Communiloquium de Joan de Gal les (ca. 1270), tot i que no hi apareix el nom de la protagonista: Et ibidem etiam narrat de Greca femina que cum hostium classe esset excerpta ut mortem pudicicia tueretur se in mare abiecit cuius corpus littori appulsum et sepulture mandatum est. Manifestatum est et eius memoria Grecis lauidbus celebranda (III.1.3).

Metge, que exalça l'acció d'Hipo i l'eleva al nivell de la cèlebre Lucrècia, condensa la breu narració de Valeri Màxim, afegeix el detall de la bellesa de la jove i suprimeix la menció al lloc i als fets succeïts després de la mort. L'exemple d'Hipo no apareixia en la font més directa del passatge de la lloa dels comportaments femenins virtuosos, l'epístola de Petrarca. En aquest mateix passatge Metge ja havia rescatat el naturalisme de Valeri Màxim en l'anècdota d'una filla que alletava el seu pare en la presó, matisat per Petrarca (Butinyà 2007: 243). El motiu de la selecció de la figura d'Hipo per part de Metge rau, molt probablement, en la seva aparició entre les cent sis biografies de dones il lustres recollides en el De claris mulieribus boccaccià:

\footnotetext{
Hyppo greca fuit mulier, ut ex codicibus veterum satis percipitur; quam vix credam unico tantum optimo valuisse opere, cum ad altiora conscendamus gradibus, eo quod nemo summus repente fiat. Sed postquam vetustatis malignitate et genus et patria ac cetera eius facinora sublata sunt, quod ad nos usque venit ne pereat, aut illi meritum subtrahatur decus, in medium deducere mens est.
}

6 El mateix rei Joan recorda a Bernat la familiaritat amb Valeri Màxim en el llibre I: «Valèrius Màximus dix en diversos lochs e creegué la dita immortalitat; però bé ho saps tu, qui l’has assats familiar» (2007: 94). 


\begin{abstract}
Accepimus igitur Hypponem hanc casu a nautis hostibus captam. Que cum forte forma valeret sentiretque predonum in se pudicitiamque suam teneri consilium, tanti castitatis decus existimavit, ut cum, nisi per mortem servari posse cerneret, non expectata violentia, in undas se dedit precipitem; a quibus sublata vita et pudicitia servata est.
\end{abstract}

Quis tam severum mulieris consilium non laudet? Paucis quidem annis, quibus forsan vita protendi poterat, castitatem redemit et immatura morte sibi perenne decus quesivit. Quod virtutis opus procellosum nequivit mare contegere nec desertum auferre litus quin literarum perpetuis monimentis suo cum bonore servaretur in luce. Corpus autem postquam ab undis aliquandiu ludibrii more volutatum est, ab eisdem in eritreum litus inpulsum, a litoranis naufragi ritu sepultum est. Tandem cum ferret ab hostibus exorta fama quenam foret et mortis causam, ab Eritreis summa cum veneratione sepulcri locus in litore ingenti tumulo atque diu mansuro, in servati decoris testimonium, exornatus est, ut noscamus quoniam nullis adverse fortune tenebris lux possit obfuscari virtutis. (LVIII)

Boccaccio amplia la narració del llatí, amb la referència a la bellesa extraordinària de la noia, i s'esplaia en l'explicació i significat del túmul erigit en la seva memòria.

Fem notar que Metge utilitza, per boca de Bernat, en la referència a Hipo el mot «fembra», el qual, com hem subratllat anteriorment, apareix en un escàs nombre de vegades en aquest personatge enfront del sinònim «dona» (5/46). Segons l'estudi de Bastardas, la distribució dels dos mots suggereix un ús estilístic: «El mot fembra és emprat sobretot quan es vol dir mal de les dones i el mot dona es fa servir per a indicar la mera feminitat» (1993: 16). Precisament el cas d'Hipo és un dels tres exemples citats per Bastardas de la utilització per part de Bernat del terme «fembra» sense cap connotació despectiva (1993: 13), essent-ne els altres dos els de la romana Cornèlia i el de Maria, la mare de Déu. De manera que aquests tres ${ }^{7}$ exempla de dones virtuoses constituirien l'excepció a la conclusió de l'estudi de Bastardas: «En Bernat Metge podem dir que fembra és el mot del misogin» (1993: 17). L'explicació suggerida per Bastardas per a la distribució dels termes seria la dependència de la font marc del passatge -el Corbaccio-, on el narrador empra preferentment donna i la figura que representa l'actitud misògina, femmina.

Ara bé, el discurs de Bernat de l'apologia de les virtuts femenines depèn no ja del Corbaccio, sinó de l'epístola de Petrarca (Fam. XXI, 8), seguida fidelment pel barceloní. L'exemple de Cornèlia, la il lustre matrona romana, palesa l'absència de connotacions negatives en l'ús del terme «fembra» $\mathrm{O}$ el seu corresponent llatí femina, que no apareix en les línies dedicades a Cornèlia en l'epístola, però sí en altres passatges i en el mateix títol que l'encapçala amb un valor manifestament elogiós: $A d$ Annam imperatricem, responsio congratulatoria super eius femineo licet partu et ob id ipsum multa de laudibus feminarum.

En el cas de Cornèlia, Petrarca la presenta succintament amb els trets més representatius d'aquesta figura en la tradició antiga, en la línia de Plutarc, Tàcit i Valeri Màxim: com a filla -Africani filiam-

\footnotetext{
7 Localitzem altres ocurrències del terme en boca de Bernat amb sentit positiu: «E que les Sibil les. les quals segons que diu Marchus Varró són estades X en nombre, fembres notables e de diverses nacions e edats, hagen profetat de l'adveniment dessús dit?» (2007: 238), que reflecteix fidelment la font petrarquesca divinas feminas.
}

SCRIPTA, Revista internacional de literatura i cultura medieval i moderna, núm. 18 / desembre 2021 / pp. 1-14 ISSN: 2340-4841 · doi:10.7203/SCRIPTA.18.22350 
i sobretot com a mare -Gracchorum matrem-, i en subratlla la fortalesa d'ànim. El terme escollit per designar-ne la feminitat és mulier, més apropiat per a una matrona, que apareix quan Petrarca expressa la seva valoració personal: quin se non miseram sed felicem diceret, que tales filios genuisset; digna, me iudice, mulier que tales pareret, indigna que perderet. ${ }^{8}$ Metge, malgrat que subministra una versió força literal del text petrarquesc que li serveix de font -el cas de Cornèlia, llevat de la breu menció com a mare de Semprònia, no apareix en De claris-, ofereix el mot català corresponent a femina: «ans dehia que era una de las pus benaventurades fembres del món, com havia concebut aytals fills. Cert, a mon juý, digna fo ésser stada mare d'aquells e indigna de haver-los perduts» (2007: 244).

La referència metgiana a Hipo no procedeix de Fam. XXI 8, sinó de Valeri Màxim i el De claris mulieribus. Com observem, en el text llatí de Boccaccio s'empra exclusivament el terme mulier -Hyppo greca fuit mulier / Quis tam severum mulieris consilium non laudet?. Per contra, Valeri Màxim sí fa servir el mot llatí corresponent a «fembra»-Graeca femina nomine Hippo-, femina, ${ }^{9}$ que no recull en cap cas els matisos pejoratius associats al terme català. Sembla, doncs, força evident que en l'exemple d'Hipo Metge escull l'opció que li subministra la font clàssica (fembra-femina), malgrat que completa la referència d'Hipo amb la lectura de De claris, la qual li proporciona explícitament el detall de la bellesa (forma) de la donzella, absent en Valeri Màxim. El record dels clàssics s'accentua conscientment, també en el lèxic, en els passatges en què Metge empra com a fonts autors com Valeri Màxim o Petrarca.

\section{Conclusions}

En Lo somni les anècdotes de Lucrècia i Hipo remeten inequívocament al valor moral de dues figures femenines, heroiques fins a l'extrem final i víctimes de la luxúria incontinent dels barons, únics culpables de la seva dissortada fi. Ambdues representen igualment dones coratjoses, model de comportaments virtuosos, que prenen amb determinació ferma la decisió d'acabar amb la pròpia vida per si mateixes. Són víctimes de la violència masculina, però es donen mort virilment (VAL.MAX. VI.1.1) exercint la seva llibertat. Metge persegueix un equilibri de la tradició romana -Lucrècia- i la grega -Hipo-, combina una referència cèlebre amb una altra poc coneguda. En

8 Sembla reelaborat a partir del text sobre l'amor conjugal de Valeri Màxim: Itaque Corneliam nescio utrum feliciorem dixerim, quod talem nirum babuerit, an miseriorem, quod amiserit (VAL. MAX, 4.6.1).

9 Els diccionaris recullen els significats habituals del mot femina: femelle, femme, par opposition au mâle (Ernout-Meillet 2001: 224); femme // femelle// genre femenin (Gaffiot 1984: 658); A. Of buman beings, a female, woman // Of beasts, a female, she // Gramm. the feminine gender (Lewis and Short). Se subratlla la tendència a diferenciar femina de mulier. Mentre mulier és un terme que designa la dona de manera més general i especialment la dona casada per oposició a la donzella (uirgo), no s'aplica mai, en canvi, a les femelles dels animals (Lewis and Short; Ernout-Meillet 2001: 418); "Aussi tend-on à différencier femina de mulier: Isid., Dif. I 588, femina... naturale nomen est, generale mulier, Tert., Or. 22, Euam nondum uirum expertam deus mulierem ac feminam cognominauit, feminam qua sexus generaliter, mulierem qua gradus specialiter» (Ernout-Meillet 2001: 224). Domina, relacionat etimològicament amb domus com és ben conegut, és un terme que designa la mestressa o senyora de la casa (Ernout-Meillet 2001: 183). 
aquests episodis selecciona, entreteixeix $\mathrm{i}$ reelabora diverses fonts clàssiques $\mathrm{i}$ italianes en llengua llatina amb notable encert. En definitiva, en l'estela de les relectures que Petrarca i Boccaccio operen sobre Valeri Màxim, es desmarca en aquesta ocasió de la tradició misògina d'autors llatins com Juvenal, Ciceró o Horaci, que reutilitza en altres moment del diàleg. Supera igualment el valor moralitzant dels exempla grecoromans a l'ús dels predicadors de l'època, que en valoraven la utilitat com a ensenyament doctrinal. S'alinea, ben al contrari, amb una actitud de defensa de la dona, allunyada de la misogínia medieval, que apareix, en canvi, en boca de Tirèsies, l'oponent de Bernatpersonatge, en un plantejament ideològic que cal situar en els corrents culturals més avançats del seu temps, oberts ja a noves perspectives literàries.

\section{Bibliografia}

Badia, L. (ed.) (1999) Metge, Bernat. Lo somni, Barcelona, Quaderns Crema.

Badia, L. \& Gómez, F. J. (2015-2016) "El Tirèsies nou de Lo somni de Bernat Metge”, Butlletí de la Reial Acadèmia de Bones Lletres de Barcelona, LV, pp. 23-58.

Bastardas, J. (1993) "Fembra i dona en Lo Somni de Bernat Metge", Revista de l'Alguer, pp. 11-20.

Battaglia, S. (1965) La coscienza letteraria del Medioevo, Nàpols, Liguori.

Boccaccio, G. (1951) Genealogie deorum gentilium libri, Vincenzo Romano (ed.), Bari, G. Laterza.

Boccaccio, G. (1967) De mulieribus claris, dins Zaccaria V. (ed.), Tutte le opere di Giovanni Boccaccio, Milano, Mondadori.

Boethius (1990) Consolatiophilosophiae, Gigon, Olof \& Gegenschatz, Ernst (eds.), München, Artemis.

Butinyà, J. (1994) “Cicerón, Ovidio, Agustín y Petrarca en Lo somni de Bernat Metge”, Epos, 10, pp. 173-201.

Butiñá, J. (2006) “Técnica y arte del retrato y del autorretrato en Bernat Metge", Revista de Lenguas y Literaturas catalana, gallega y vasca, 12, pp. 27-44.

Butiñá, J. (ed.) (2007) Lo somni. El sueño, Madrid, Centro de Lingüística Aplicada Atenea.

Butinyà, J. (2011) "Lo somni, entre l’Àfrica i el Secretum”, dins Júlia Butinyà i Antonio Cortijo eds. L'Humanisme a la Corona d'A ragó (en el context bispànic i europeu), Potomac, Scripta Humanistica, pp. 61-78.

Ciceronis, M. Tulli (1965), Orationes I, Clark, Albertus Curtis (ed.), Oxford, OUP.

Cingolani, S. M. (1999) “Lo somni de Bernat Metge: prolegòmens per a una nova edició”, Llengua \& Literatura, 10, pp. 245-278.

Cingolani, S. (ed.) (2006) Bernat Metge. Lo somni, Barcelona, Barcino. 
Corominas, J. (1987) Breve diccionario etimológico de la lengua castellana, Madrid, Gredos.

Curran, L. (1978) "Rape and rape victims in the Metamorphoses", Arethusa, 11, pp. 213-241.

Ernout, \& Meillet, A. (2001 [1a ed. 1932]), Dictionnaire étymologique de la langue latine. Histoire des mots, Paris, Klincksieck.

Fenzi, E. (2012) "Lo somni di Bernat Metge e Petrarca: Platone e Aristotele, oppinió e sciència çerta", dins Cabré. L., Coroleu, A. \& Kraye, J. eds. Fourteenth-Century Classicism: Petrarch and Bernat Metge, The Warburg Institute/Nino Aragno, London /Turin, pp. 85-108.

Friedlein, R. (2004) "Mitologia antiga i forma dialògica en Lo somni de Bernat Metge (1398)", dins R. Friedlein \& S. Neumeister eds. "Vestigia fabularum." La mitologia antiga a les literatures catalana $i$ castellana entre l'edat mitjana i la moderna, Barcelona, Publicacions de l'Abadia de Montserrat, pp. 65-83.

Fulgentius, Flavius Planciades (1898) Opera, Helm, R., (ed.), Leipzig, Teubner. https://www.hsaugsburg.de/ harsch/Chronologia/Lspost06/Fulgentius/ful myt0.html [13 de juny 2021]

Gaffiot, F. (1934) Dictionnaire Illustré Latin-Français, Paris, Hachette.

González Delgado, R. (2003) “Interpretaciones alegóricas del mito de Orfeo y Eurídice por Fulgencio y Boecio y su pervivencia en la Patrologia Latina”, Faventia, 25/2, pp. 7-35.

Gros Lladós, Sònia (2013) “Sobre el passatge final de Lo somni i la presència del Secretum”, eHumanistal IVTTRA, 4, pp. 73-96.

Hernández, M. (1997) “Boccaccio y el mundo clásico”, Amal, 20, pp. 73-94.

Horati Flacci, Q. (1901) Opera, H. W. Garrod (ed.), Oxford, OUP.

Joan de Gal les (1475) Communiloquium siue Summa de Collationibus. Augsburg, https://manipulusproject.wlu.ca/Communiloquium.pdf [11 de juny de 2021].

Juvénal (1921) Satires, Pierre de Labriolle et François Villeneuve (eds.), Paris, Les Belles Lettres.

Kempf, K. F. (1888) Valerius Maximus. Factorum et Dictorum Memorabilium Libri Nouem, Lepizig, Teubner.

Lewis, Charlton T. \& Short, Ch. (1879) A Latin Dictionary, Oxford, Clarendon Press.

Livius, T. (1898) The History of Rome, Book 1, Weissenborn W., Müller H.J. (eds), Leipzig, Teubner, en: Perseus Digital Library, http://www.perseus.tufts.edu/hopper/ text?doc $=$ Perseus\%3atext\%3a1999.02.0198 [2 de maig de 2021].

Moreno, R., (ed.) (2011) Diccionario de motivos amatorios en la Literatura Latina (Siglos III a.C.-II d.C.), Huelva, Universidad de Huelva (Exemplaria Classica).

Ovidi (1977), Art amatòria, Pérez Durà, J. (ed.), Barcelona, Col lecció Bernat Metge.

Ovidi (1929-1932), Les Metamorfosis, 3 vol., Adela M. Trepat \& Anna Maria de Saavedra (eds.), Barcelona, Col lecció Bernat Metge. 
Ovidius Naso, P. (1933) Fasti, J.G. Frazer (ed.), London, Cambridge, MA., William Heinemann Ltd., Harvard University Press, en: Perseus Digital Library, http://www.perseus.tufts.edu/hopper/ [11 de juliol de 2021].

Petrarca (2011), Mi secreto. Arqués, Rossend (ed.), Madrid, Cátedra.

Petrarca, F. (1942). Le Familiari, IV, V. Rossi (ed.), Firenze, Edizione Nazionale delle Opere di Francesco Petrarca XIII.

Petronio (1968-69), Satiricón, 2 vol., Manuel Díaz y Diaz (ed.), Madrid, CSIC.

Properci (1946) Elegies, Josep Vergés (ed.), Barcelona, Col lecció Bernat Metge.

Rovira, H. (2014) El Valeri Màxim d'Antoni Canals: estudi i edició (llibres I-V), Barcelona, Universitat de Barcelona.

Rovira Cerdà, H. (2015) “Els exempla de Valeri Màxim a la literatura catalana medieval”, Scripta, 5, pp. 21-51.

Ruiz Simon, J. M. (2002) "Lo somni de Metge: el malson filosòfic d'un epicuri”, dins L. Badia, M. Cabré \& S, Martí (eds.), Literatura i cultura a la Corona d'Aragó, segles XIII-XV, Barcelona, Publicacions de l'Abadia de Montserrat, pp. 25-47.

Senecae, L. A. (1986) Tragoediae, Otto Zwierlein (ed.), Oxford, OUP.

Valerius Maximus (1888), Factorum et dictorum memorabilium libri nonem, C. Kempf (ed.), Leipzig, en: Bibliotheca Augustana, http://www.hs-augsburg.de/ harsch/Chronologia/Lspost01/ Valerius//val fac6.html\#01 [20 de maig de 2021].

Vergili Maronis, P. (1969) Opera, Roger Mynors (ed.), Oxford, OUP.

Vilanova, A. (1957-1958) "La génesis de Lo somni de Bernat Metge", Boletín de la Real Academia de Buenas Letras de Barcelona, 27, pp. 123-156. 